DOI

http://dx.doi.org/10.15448/1983-4012.2015.2.18448

\title{
A IDEIA DO DIREITO E A SUA EFETIVAÇÃO COMO PRESSUPOSTOS DA PAZ PERPÉTUA DE KANT
}

The idea of right and its realization as assumptions of perpetual peace of Kant

João Tescaro Junior *

Resumo:: Investiga a ideia do direito e a sua concretização histórica como conditio sine qua non da ideia de paz duradora. Inicialmente, considerando os textos histórico-filosóficos de Kant, mostra como ele constrói as bases da ideia do direito sobre sua filosofia da história e, também, como ele modifica sua teoria entre os seus primeiros e últimos textos históricofilosóficos. Na sequência, evidencia como Kant procura aterrar a razão prática e, com isso, entender a realização histórica da ideia do direito na forma de um mecanismo de aprendizagem político-cultural. Ainda, destaca a construção da ideia do direito e dos seus principais elementos teóricos.

Palavras-chave: Kant, Direito, História, Paz perpétua.

\begin{abstract}
Investigates the idea of right and its historical realization as conditio sine qua non of the idea of perpetual peace. Initially, considering the historical-philosophical texts of Kant, shows how he builds the foundations of the idea of right about his philosophy of history, and also how he modifies his theory between his first and last historical-philosophical texts. Further, shows how Kant tries to land the practical reason and, thus, understand the historical realization of the idea of right as a mechanism of political-cultural learning. Also highlights the construction of the idea of right and of its main theoretical elements.
\end{abstract}

Keywords: Kant, Right, History, Perpetual peace.

\footnotetext{
* Mestre em Filosofia pela Universidade Estadual de Londrina (UEL). Email: jtescarojr@gmail.com
}

\begin{tabular}{|c|c|l|l|c|c|}
\hline intuitio & $\begin{array}{c}\text { ISSN } \\
1983-4012\end{array}$ & Porto Alegre & Vol.8 $-\mathrm{N}^{\mathrm{o}} .2$ & $\begin{array}{c}\text { Dezembro } \\
2015\end{array}$ & p.25-42 \\
\hline
\end{tabular}




\section{Introdução}

Como Kant desenvolve os fundamentos histórico-filosóficos da ideia do direito? É possível relacionar a ideia do direito a um processo de aprendizagem social? Qual é a importância da ideia do direito para o ideal de paz duradoura? Na tentativa de encontrar respostas para estes questionamentos, a presente pesquisa foi desenvolvida em três tópicos distintos. No primeiro, procuramos entender como Kant desenha os fundamentos da ideia do direito no âmbito da sua filosofia da história e por que a sua teoria oscila em atribuir a efetivação do direito ora à "natureza", ora ao dever moral dos homens e ora aos dois conjuntamente. Nessa ordem de ideias, no segundo, investigamos o modo como o filósofo de Königsberg arquiteta e desenrola os argumentos sobre os indícios e sinais do progresso político e dá margem para que se possa compreender a efetivação histórica da ideia do direito como um mecanismo de aprendizagem social. No terceiro, a pesquisa procura mostrar como Kant constrói da ideia do direito colocando em destaque as ideias de trânsito do estado de natureza ao estado jurídico, de coerção e de publicidade.

\section{Os fundamentos histórico-filosóficos da ideia do direito em Kant}

A filosofia política kantiana pode ser compreendida de forma ampla somente mediante a consideração da sua filosofia da história ${ }^{1}$, a qual, através de princípios heurístico-regulativos, procura engendrar de forma teórica uma unidade sistemática de sentido pela qual os fatos desagregados e, muitas vezes, colidentes da história humana são a priori planejados e organizados, como se fossem um todo ordenado, no intuito de abrir os horizontes da razão prática ${ }^{2}$. Nesse passo, a "natureza" leva o homem

\footnotetext{
${ }^{1}$ Nesse sentido, Klemme afirma que "Kant foi seguramente convicto de que a questão da efetivação das condições públicas legais, isto é, a questão sobre as condições sob as quais os postulados do direito são politicamente efetivados, precisa ser respondido no contexto da filosofia da história. [...] Sem sua filosofia da história sua filosofia política não pode ser entendida". KLEMME, Heiner. "Filosofia política de Kant - moral e direito na perspectiva histórica e futura". In: Kant e-Prints, Campinas, Série 2, v. 5, n. 4, número especial, jul./dez., 2010, p. 08. Também a esse respeito, Herrero explica que "da [...] consideração sobre a possibilidade do Soberano Bem político vai surgir nada menos que a filosofia kantiana da história com toda a sua peculiaridade". HERRERO, Francisco Javier. Religião e história em Kant. São Paulo: Loyola, 1991, p. 119. Em razão da inseparabilidade e da convergência dos dois campos de estudos, Georg Cavallar arrisca chamá-las filosofia política da história. CAVALLAR, Georg. "A sistemática da parte jusfilosófica do projeto kantiano à paz perpétua". In: ROHDEN, Valério (coord.). Kant e a instituição da paz. Porto Alegre: Ed. Universidade/UFRGS, Goethe-Institut/ICBA, 1997, p. 89.

${ }^{2}$ De acordo com Allen Wood, a filosofia da história de Kant pode ser entendida de dois modos inteiramente separados e independentes. De um lado, ela mostra-se como interesse teórico da razão, segundo o qual há a necessidade de se alcançar a sistematicidade e inteligibilidade racional nas ações humanas arbitrárias, nos fatos acidentais e na multiplicidade das ocorrências históricas, os quais acabam por receber um sentido históricoteleológico compreensível que aponta para a existência de um fim último da espécie. De outro, ela é vista como interesse prático da razão, pelo qual os homens são considerados fins em mesmos e, por isso, moralmente responsáveis pela organização e efetivação de uma ordem política pacífica e justa que, ao assegurar a liberdade externa, propicia o completo desenvolvimento de suas disposições racionais. Apesar de se poder compreendê-la
}

\begin{tabular}{|c|c|c|c|c|c|}
\hline intuitio & $\begin{array}{c}\text { ISSN } \\
1983-4012\end{array}$ & Porto Alegre & Vol.8 $-\mathrm{N}^{\circ} .2$ & $\begin{array}{c}\text { Dezembro } \\
2015\end{array}$ & p.25-42 \\
\hline
\end{tabular}


A ideia do direito e a sua efetivação como pressupostos da paz perpétua de Kant

àquele seu fim último para prepará-lo para aquilo que ele próprio tem que fazer para tornar-se o fim terminal $^{3}$ ou, como outrora fora expresso na Ideia de uma história universal de um ponto de vista cosmopolita, para que ele tenha condições de "tirar tudo de si mesmo" e, assim, ser autor da sua própria felicidade e perfeição e ser digno da sua vida e bem-estar ${ }^{4}$. Todavia, embora a natureza tenha dotado o homem de razão e liberdade da vontade, fornecendo, assim, um claro indício de como o seu fim último deveria ser atingido, Kant não descarta a sua intervenção na consecução do seu mais alto propósito 5 .

A condição formal para que o fim último da natureza seja alcançado é a instituição de uma sociedade civil cujo estado jurídico restringe a liberdade em conflito dos homens ${ }^{6}$. Na Doutrina do direito esta situação jurídica surge na forma do direito racional que se configura como a soma das condições sob as quais se dá a conciliação dos arbítrios individuais conforme uma lei universal da liberdade ${ }^{7}$. Segundo Kant, é dever dos homens saírem do estado de natureza por meio da instituição de uma sociedade civil justa e pacífica, ainda que não exista a menor probabilidade teórica da sua efetivação, sendo que a impossibilidade de demonstrar ${ }^{8}$ a sua concretização no mundo empírico não desautoriza o dever de agir como se tal ideia fosse algo real ou realizável, pois não se pode provar que ela é tampouco que ela não é . A própria "razão prático-moral", mediante a "reforma paulatina, de acordo com sólidos princípios", exige dos homens a efetivação do "fim último [...] da doutrina do Direito nos limites da simples razão"10. Conforme explica Klemme, Kant considera a história o âmbito no qual se realiza o direito racional ${ }^{11}$, porém transparece que a base filosófica de efetivação histórica da ideia do direito sofre considerável alteração nos escritos kantianos posteriores ao texto Ideia de uma história universal de um ponto de vista cosmopolita.

Apesar de o Kant tardio atribuir aos homens o dever de efetivarem a sociedade civil cosmopolita de paz universal ${ }^{12}$, não se pode deixar de notar que ele, em seus primeiros textos histórico-filosóficos,

dessa forma, Wood esclarece que estas duas perspectivas são intimamente ligadas e confluentes, porque, na medida que a inteligibilidade histórica atribui racionalidade às ações humanas, é franqueada a via para as esperanças e objetivos morais como o esclarecimento, o progresso moral e a paz perpétua. WOOD, Allen W. "Kant's philosophy of history". In: KLEINGELD, Pauline (org). "Toward perpetual peace" and other writings on politics, peace, and history. New York: Yale University Press, 2006, p. 244, 254 e 255.

${ }^{3}$ KANT, Immanuel. Crítica da faculdade do juízo. 2 ed. Rio de Janeiro: Forense Universitária, 2010, p. 271.

${ }^{4}$ KANT, Immanuel. Idéia de uma história universal de um ponto de vista cosmopolita. 2 ed. São Paulo: Martins Fontes, 2004, p. 6 e 7.

${ }_{6}^{5}$ KANT, Immanuel. Idéia de uma história universal de um ponto de vista cosmopolita, p. 6.

${ }^{6}$ KANT, Immanuel. Crítica da faculdade do juízo, p. 271.

${ }^{7}$ KANT, Immanuel. A metafísica dos costumes. 2 ed. Lisboa: Fundação Calouste Gulbenkian, 2011, p.43.

${ }^{8} \mathrm{Na}$ Crítica da razão pura Kant já afirmara que "é totalmente impossível demonstrar que uma disposição da natureza, seja ela qual for, não tenha qualquer finalidade”. KANT, Immanuel. Crítica da razão pura. 7 ed. Lisboa: Fundação Calouste Gulbekian, 2010, p. 561.

${ }^{9}$ KANT, Immanuel. A metafísica dos costumes, p. 243.

${ }^{10}$ KANT, Immanuel. A metafisica dos costumes, p. 243-244.

${ }^{11}$ KLEMME, Heiner. "Filosofia política de Kant - moral e direito na perspectiva histórica e futura", p. 8.

${ }^{12} \mathrm{O}$ cosmopolitismo kantiano diferencia-se daqueles modelos baseados no cinismo e no estoicismo, embora se aproxime mais deste último. O cosmopolitismo cínico, que tem em Diógenes de Sinope a sua figura mais conhecida,

\begin{tabular}{|c|c|l|l|c|c|}
\hline intuitio & $\begin{array}{c}\text { ISSN } \\
1983-4012\end{array}$ & Porto Alegre & Vol.8 $-\mathrm{N}^{\mathrm{o} .2}$ & $\begin{array}{c}\text { Dezembro } \\
2015\end{array}$ & p.25-42 \\
\hline
\end{tabular}


A ideia do direito e a sua efetivação como pressupostos da paz perpétua de Kant

delega à "natureza" esta tarefa. Com efeito, na Ideia de uma história universal de um ponto de vista cosmopolita e no Começo conjectural da história humana, o direito é vinculado a fatores genéticos (insociável sociabilidade, egoísmo natural, desejo por honrarias, ânsia por dominação, busca de projeção, cobiça) que coagem os homens a entrarem no estado civil. Nestes textos, não é o dever incondicional que obriga os homens a instituírem o direito público e a viverem pacificamente em sociedade, mas as misérias da natureza humana que os levam ao abandono do estado de natureza mediante a instituição de uma sociedade civil baseada em um acordo patologicamente extorquido ${ }^{13}$. De acordo com Terra, não é "a obrigação moral de sair do estado de natureza que levará os homens egoístas a instituírem a sociedade civil, e sim a necessidade, a miséria (Noth), especialmente a pior das misérias, que é aquela que os homens infligem uns aos outros"14.

De outro lado, nos textos Sobre a expressão corrente e A paz perpétua, embora Kant ancore o direito público à razão pura prática, para exigir dos homens a passagem do estado de natureza à sociedade civil, ele atribui à "natureza" a condição de garantia suplementar para a eventualidade dos homens não conseguirem cumprir com o seu dever. Ou seja, paralelamente ao dever do homem, Kant arquiteta uma espécie de dispositivo teórico de segurança pelo qual a "natureza", mesmo diante do "jogo da liberdade humana", "não procede sem um plano nem um propósito final"15, o qual, "quer queiramos quer não"16, nos pressiona a deixar o estado de natureza para adentrarmos o estado jurídico ${ }^{17}$ que se apresenta como "um grande passo para a moralidade" e não como um "passo moral", tratando-se, de fato, não de um problema relativo ao "aperfeiçoamento moral do homem, mas apenas do mecanismo da natureza"18.

endossa uma concepção negativa, apolítica e individualista de cidadania mundial, na medida em que não reconhece vínculos com qualquer cidade ou Estado em particular, negando, portanto, as convenções sociais localizadas. Por sua vez, o cosmopolitismo estoico adota uma concepção positiva de cidadania mundial que afirma a existência de obrigações morais entre todos os homens, independentemente de suas convicções pessoais, sem, contudo, assumir a forma jurídica por meio de instituições políticas cosmopolitas com responsabilidade globais. Não obstante tenha experimentado a influência deste último modelo, o cosmopolitismo kantiano não advoga apenas um cosmopolitismo moral voltado para a efetivação de uma comunidade moral de todos os povos. O modelo kantiano é inovador por conjugar o ideal estoico e a teoria do direito e do estado e, assim, desenvolver a dimensão moral de uma cidadania mundial vinculada à arranjos institucionais cosmopolíticos. Nesse sentido: KLEINGELD, Pauline. Kant and cosmopolitanism: the philosophical ideal of world citizenship. Cambridge: Cambridge University Press, 2011, p. 2 e 3; HÖFFE, Otfried. A democracia no mundo de hoje. São Paulo: Martins Fontes, 2005, p. 274, 275 e 301.

${ }_{13}^{13}$ KANT, Immanuel. Idéia de uma história universal de um ponto de vista cosmopolita, p. 9.

${ }^{14}$ TERRA, Ricardo R. A política tensa: idéia e realidade na filosofia da história de Kant. São Paulo: Iluminuras, 1995, p. 163.

${ }^{15}$ KANT, Immanuel. Idéia de uma história universal de um ponto de vista cosmopolita, p. 20.

${ }^{16}$ KANT, Immanuel. "A paz perpétua”. In: KANT, Immanuel. A paz perpétua e outros opúsculos. Lisboa: Edições 70, 2009, p. 158.

${ }^{17}$ KLEMME, Heiner. "Filosofia política de Kant - moral e direito na perspectiva histórica e futura", p. 28.

${ }^{18}$ KANT, Immanuel. "A paz perpétua", p. 159 e 171. A ideia de mecanismo da natureza, da qual fala Kant, é uma assunção heurística-regulativa que não pode ser interpretada dogmaticamente no sentido constitutivo, ou seja, como um dado empírico cognoscível. Segundo ela, a história humana é dirigida por uma teleologia natural inconsciente e oculta que se serve dos impulsos humanos psicogenéticos para o "desenvolvimento continuamente progressivo" das "disposições originais" dos homens no âmbito da própria espécie como um todo. KANT, Immanuel. Idéia de uma história universal de um ponto de vista cosmopolita, p. 3-6.

\begin{tabular}{|c|c|l|l|c|c|}
\hline intuitio & $\begin{array}{c}\text { ISSN } \\
1983-4012\end{array}$ & Porto Alegre & Vol.8 $-\mathrm{N}^{\mathrm{o} .2}$ & $\begin{array}{c}\text { Dezembro } \\
2015\end{array}$ & p.25-42 \\
\hline
\end{tabular}


A ideia do direito e a sua efetivação como pressupostos da paz perpétua de Kant

Em Sobre a expressão corrente, Kant aponta de forma expressa essa garantia suplementar da natureza, que Klemme denomina princípio subsidiário ${ }^{19}$, na qual ele confia in subsidium (subsidiariamente) à "natureza" o escopo de efetivar a sociedade cosmopolita pacífica se os "deuses da Terra" não procederem de forma a "introduzir-se assim tal Estado universal dos povos e a supor também que ele é possível (in praxi) e que pode existir". Na hipótese da boa vontade não fazer o que deve ser feito, a impotência derivada da violência omnilateral e suas misérias dará conta de fazê-lo ${ }^{20}$. Nesse caso, segundo Herrero, a natureza assume a forma de "artífice que garante a realização da paz perpétua por meio do mecanismo das inclinações humanas e pela guerra" ${ }^{\text {"21 }}$. Embora a figura garantidora da "natureza" atue de forma subsidiária nesses dois últimos textos, podemos afirmar que o seu papel é de destaque frente ao dever 22 , porque se "a natureza quer a todo custo que o direito conserve, em último termo, a supremacia" e se o homem "não faz" aquilo que "devia fazer segundo as leis da liberdade"23, então a natureza, mediante seus próprios recursos (tendências egoístas, violência omnilateral, guerras), fará surgir a harmonia interna e externa entre os povos ${ }^{24}$.

Se não se pode negar que a "natureza" foi a "grande artista" 25 da efetivação do direito até $A$ paz perpétua, também não pode passar despercebido que na Doutrina do direito e em $O$ conflito das faculdades ela tem o seu papel fortemente substituído pelo dever moral dos homens de conviverem juridicamente. Nesse primeiro texto, o conceito de direito é vinculado a uma obrigação que lhe é correspondente, a qual Kant chama de conceito moral de Direito que pode ser entendido como um "imperativo moral [...] que prescreve o dever" do qual pode ser desenvolvido o "conceito de direito" que é a "faculdade de obrigar outrem" (grifo meu) ${ }^{26}$. Igualmente, em $O$ conflito das faculdades, ao falar sobre o

${ }^{19}$ KLEMME, Heiner. "Filosofia política de Kant - moral e direito na perspectiva histórica e futura", p. 40.

${ }^{20}$ KANT, Immanuel. "Sobre a expressão corrente". In: KANT, Immanuel. A paz perpétua e outros opúsculos. Lisboa: Edições 70, 2009, p. 106, 107 e 109.

${ }^{21}$ HERRERO, Francisco Javier. Religião e história em Kant, p. 132.

${ }^{22}$ Com a análise desse viés da filosofia da história kantiana, Honneth afirma que, em última instância, somente esse resseguro, baseado na intenção da natureza, fornece ao ator moral um sentimento de garantia de que, por meio de seus próprios esforços, contribui para o andamento do processo rumo ao bem. HONNETH, Axel. Pathologies of reason: on legacy of critical theory. New York: Columbia University Press, 2009, p. 3.

${ }^{23}$ KANT, Immanuel. "A paz perpétua", p. 157 e 159.

${ }^{24}$ Não obstante a "natureza" ser a principal responsável pela consecução do fim último, em A paz perpétua, Kant esclarece que a natureza não causa dano à liberdade da vontade porque não impõe o dever de fazer qualquer coisa, uma vez que este só pode ter origem na "razão prática isenta de coacção". KANT, Immanuel. "A paz perpétua", p. 157 e 158.

${ }^{25}$ KANT, Immanuel. “A paz perpétua”, p. 151.

${ }^{26}$ KANT, Immanuel. A metafísica dos costumes, p. 43 e 60. Nosso objetivo não é polemizar a respeito da existência de fundamento moral do direito na filosofia de Kant nem reconstruir as principais teses sobre este assunto. Todavia, cumpre destacarmos que a questão a respeito da fundamentação da validade das leis jurídicas no imperativo categórico é bastante controversa dentre os intérpretes de Kant. Com efeito, ao elaborar a sua filosofia prática na Metafísica dos costumes, Kant apresenta a moral em sentido amplo e suas derivações nas formas de leis jurídicas e leis éticas, sendo que as primeiras se referem ao exercício externo da liberdade e as segundas ao seu exercício interno. Disso resulta, de um lado, as interpretações tradicionais que, a exemplo da tradição filosófica anglofônica, tendem a englobar a filosofia política de Kant em sua filosofia moral, notadamente na forma como ela foi expressa

\begin{tabular}{|c|c|l|l|c|c|}
\hline intuitio & $\begin{array}{c}\text { ISSN } \\
1983-4012\end{array}$ & Porto Alegre & Vol.8 $-\mathrm{N}^{\circ} .2$ & $\begin{array}{c}\text { Dezembro } \\
2015\end{array}$ & p.25-42 \\
\hline
\end{tabular}


A ideia do direito e a sua efetivação como pressupostos da paz perpétua de Kant

entusiasmo advindo da "revolução de um povo espiritual", Kant esclarece que o verdadeiro entusiasmo é aquele decorrente do ideal puramente moral que é o conceito de direito ${ }^{27}$. Nessa linha, Hamm explica que neste último texto Kant promove uma guinada argumentativa significante, uma vez que ele destaca o papel do homem como agente autônomo na história, a importância da ideia do direito e a autodeterminação jurídica como elementos necessários para a realização do progresso histórico ${ }^{28}$.

Não obstante Hamm reconheça a mudança da tônica discursiva de Kant, ele, em debate com Reinhard Brandt, afirma que isso não implica que as figuras teleológicas e regulativas da filosofia da história kantiana tenham sido abandonadas ou perdido a sua função argumentativa, mormente porque o referido texto não mostra claramente esta mudança teórica. Todavia, a esse respeito existem detalhes que não podem ficar sem serem notados na Doutrina do direito (1797) e em $O$ conflito das faculdades (1798), os quais, se não indicam o completo abandono do discurso heurístico e regulativo da natureza para sustentar o progresso histórico da humanidade ${ }^{29}$, mostram, ao menos, considerável redução do seu significado no fechamento sistemático da filosofia da história de Kant. Para fundamentar esse ponto de vista, podemos arguir que, na Doutrina do direito, além de Kant deixar de usar o princípio heurístico-regulativo da natureza para apoiar o dever moral de instituição da sociedade civil pacífica, ele demonstra clara indignação contra a forma de pensamento que, por um lado, desconsidera a lei moral e o dever como

na Fundamentação. Por esse viés, o direito é fundamentado na moral e tal relação de fundamentação é uma relação forte (conceito moral de direito). Nesse sentido, Dutra parece adotar o entendimento segundo o qual os deveres de direito são considerados uma subclasse dos deveres éticos, portanto, o direito tem uma relação forte com a moral. De outro lado, estão os intérpretes que compreendem que o direito apenas garante a liberdade exterior, sem manter qualquer relação com a moral (conceito liberal de direito). Nesse passo, Wood e Feldhaus, sem desconsiderarem a primeira corrente, assumem a posição de que direito e moral possuem naturezas diversas, uma vez que o primeiro não obriga fins ou a consciência e a segunda sim. Por sua vez, Gomes, ao apresentar longamente as duas teses, afirma que ambas contam com bons argumentos e que a tensão entre o conceito liberal e o conceito moral não se resolve na filosofia política kantiana. Nesse sentido: KANT. Metafísica dos costumes, p. 19, 20 e 60; DUTRA, Delamar J. V. "A conexão entre moral e direito em Kant”. In: FELDHAUS, Charles. Direito e moral: três estudos a respeito da filosofia prática de Kant. Florianópolis: Apolodoro, 2007, p. 8-13; FELDHAUS, Charles. Direito e moral: três estudos a respeito da filosofia prática de Kant, p. 38-41; GOMES, Alexandre Travessoni. "A relação entre direito e moral: Kant e Habermas”. In: FRANKENBERG, Günter; MOREIRA, Luiz (org.). Jürgen Habermas, 80 anos: direito e democracia. Rio de Janeiro: Lúmen Juris, 2009, p. 195-218; WOOD, Allen W. Kant. Porto Alegre: Artmed, 2008, p. 174-177 e 204-206.

${ }^{27}$ KANT, Immanuel. O conflito das faculdades. Lisboa: Edições 70, 1993, p. 103.

${ }^{28}$ HAMM, Christian. "Sobre a sistematizabilidade da filosofia da história de Kant". In: Veritas. Porto Alegre, v. 50, n. 1, Março/2005, p. 84.

${ }^{29}$ Segundo G. Munzel, a ideia de progresso histórico de Kant pode ser entendida como uma viagem ilimitada e com objetivos inalcançáveis que, não obstante possa experimentar interrupções e retrocessos, na perspectiva ampliada da espécie humana, mostra-se como um contínuo desenvolvimento em direção aos seus objetivos morais. Enquanto Otfried Höffe a compreende apenas como desenvolvimento político-jurídico, cujo fim terminal seria a instituição de uma ordem jurídica pacífica e justa, P. Kleingeld, R. Louden, A. Wood e E. Weil a interpretam também como progresso moral da humanidade. MUNZEL, G. Felicitas. Kant's conception of moral character: the "critical" link of morality, anthropology, and reflective judgment. Chicago/London: The University of Chicago Press, 1999, p. 170; HÖFFE, Otfried. Immanuel Kant. São Paulo: Martins Fontes, 2005, p. 274 e 275; KLEINGELD, Pauline. Kant and cosmopolitanism: the philosophical ideal of world citizenship, p. 161; LOUDEN, Robert B. Kant's impure ethics: from rational beings to human beings. New York: Oxford University Press, 2000, p. 152; WEIL, Eric. Problemas kantianos. São Paulo: Realizações, 2012, p. 111.

\begin{tabular}{|c|c|l|l|c|c|}
\hline intuitio & $\begin{array}{c}\text { ISSN } \\
1983-4012\end{array}$ & Porto Alegre & Vol.8 $-\mathrm{N}^{\mathrm{o}} .2$ & $\begin{array}{c}\text { Dezembro } \\
2015\end{array}$ & p.25-42 \\
\hline
\end{tabular}


A ideia do direito e a sua efetivação como pressupostos da paz perpétua de Kant

fundamentos do direito e, por outro, considera a espécie humana como sujeita, pelos seus próprios princípios, ao mecanismo da natureza comum a todas as espécies animais ${ }^{30}$. Em segundo lugar, em $O$ conflito das faculdades, Kant afirma que o progresso do gênero humano não diz respeito à "história natural do homem [...], mas da história moral [...] quando se pergunta se o género humano (em geral) progride constantemente para o melhor" ${ }^{\text {31 }}$. Além disso, é significativo o fato de que, neste último texto, Kant não faz qualquer menção ao fim último da natureza, mas somente ao fim terminal (Endzweck) da criação $^{32}$ que se refere exclusivamente ao mundo da moralidade.

\section{A efetivação histórica da ideia do direito como um mecanismo de aprendizagem social}

Nesse caminho de modificações conceituais, convém destacar que, em $O$ conflito das faculdades, Kant procura principalmente o sinal histórico (signum rememorativum, demonstrativum, prognostikon) ${ }^{33}$ da efetivação do progresso, e não mais a subsidiariedade da "natureza" como apoio sistemático do progresso histórico do homem. Este fato nos leva a indagar os motivos que fizeram Kant "alterar" o fio condutor da história humana e, também, nos faz imaginar que, provavelmente, ele tenha enxergado na Revolução Francesa (revolução de um povo espiritual que a si mesmo dá uma constituição civil ${ }^{34}$ ) um substituto conceitual mais adequado que, além de ter a potencialidade de sistematizar e unificar a história passada, presente e futura - como o fez o fio condutor a priori da natureza nos escritos anteriores -, tem a capacidade de não mais ser esquecido pelos homens, porque lhes revelou a sua disposição moral de progredir para o melhor, decorrente da sua dupla cidadania (sujeitos do mundus sensibilis e do mundus intelligibilis), inserta nos "princípios internos do direito" 35 .

Aliás, esse entendimento não é de todo descabido, pois, à maneira dos foguetes propulsores dos ônibus espaciais que, após cumprirem a tarefa de impulsioná-los e levá-los a determinado estágio espacial, são substituídos pela força dos motores principais das naves que, por sua vez, as impulsionam até a órbita terrestre, podemos muito bem entender que a evolução engendrada pela ideia de natureza (sistema de

\footnotetext{
${ }^{30}$ KANT, Immanuel. A metafísica dos costumes, p. 244. Ressalte-se que essa menção de Kant ao "mecanismo da natureza" não tem qualquer função regulativa na Doutrina do direito, apresentando-se somente nos limites do conhecimento teórico.

${ }^{31}$ KANT, Immanuel. O conflito das faculdades, p. 95.

${ }^{32}$ KANT, Immanuel. $O$ conflito das faculdades, p. 106. É importante destacar que, na obra utilizada, o termo fim terminal da criação vem equivocadamente traduzido como fim último da criação, pois no texto original da Academia o termo que aparece é Endzwecks (cf. AA 07: 089)

${ }^{33}$ KANT, Immanuel. $O$ conflito das faculdades, p. 101.

${ }^{34}$ Convém esclarecer que o sinal histórico do qual fala Kant não é a própria Revolução Francesa, mas o "modo de pensar" dos espectadores que assistem o povo francês dar a si uma constituição civil sem ser impedido por outros povos. KANT, Immanuel. O conflito das faculdades, p. 101.

${ }^{35}$ KANT, Immanuel. O conflito das faculdades, p. 105.
}

\begin{tabular}{|c|c|l|l|c|c|}
\hline intuitio & $\begin{array}{c}\text { ISSN } \\
1983-4012\end{array}$ & Porto Alegre & Vol.8 $-\mathrm{N}^{\mathrm{o} .2}$ & $\begin{array}{c}\text { Dezembro } \\
2015\end{array}$ & p.25-42 \\
\hline
\end{tabular}


A ideia do direito e a sua efetivação como pressupostos da paz perpétua de Kant

foguetes propulsores), ao efetivar historicamente a ideia do direito (alcançar determinado estágio), consumou a finalidade heurística a ela destinada (impulsionar para vencer a gravidade) para, doravante, delegar à figura do sinal histórico (motores principais) a responsabilidade por conduzir o restante da viagem da humanidade. Nas palavras de Kant, o "sinal histórico" da revolução, plasmado no "modo de pensar" dos espectadores que veem um povo dar-se uma constituição civil sem qualquer impedimento dos demais povos, é uma "evolução de uma constituição de direito natural" ${ }^{36}$.

Por outro lado, também é possível dizer que, em suas diversas formas (insociável sociabilidade, guerras etc.), o fio condutor da natureza mostra-se como uma instância transcendental, advinda do uso hipotético da razão, que, muitas vezes, pode apresentar-se como um expediente de difícil apreensão e compreensão e que, de mais a mais, está vinculada a "débeis indícios" que revelam "muito pouco" sobre o progresso da espécie humana, conforme exposto na Ideia de uma história universal de um ponto de vista cosmopolita $^{37}$. De fato, conforme Wood, as imagens heurísticas criadas por Kant não propiciam qualquer fiança teórica, tampouco evidências empíricas legítimas, de que o fim esperado será efetivamente alcançado no mundo, levando Kant a recorrer ao dever moral dos homens de promover o fim e esperar que ele seja logrado ${ }^{38}$. No entanto, é perceptível que mesmo quando Kant delega aos homens o dever moral de efetivarem a sociedade civil, seja em âmbito nacional ou internacional, a "natureza" funciona "subsidiariamente" na consecução deste fim, porque ela quer a qualquer modo a sua efetivação no mundo.

Isso carrega o mesmo problema apontado por Wood e, talvez, ainda o agrave, pois se a "natureza", por um lado, teria por objetivo sistematizar a história numa unidade de sentido, por outro, considerando os elementos responsáveis pela menoridade do homem (preguiça e covardia) ${ }^{39}$, a garantia da "natureza" poderia gerar uma disposição psicológica de comodismo e passividade e, por conseguinte, impedi-lo de fazer uso público da sua razão a fim de instaurar uma convivência pacífica e justa fundamentada no dever moral, porque ela sempre o estaria guiando pelas mãos. Ao final, como o deus Janus, a "natureza" teria uma face voltada para um horizonte de sentido motivador e outra, para os aspectos responsáveis pela menoridade habitual do homem, contribuindo, inclusive, para a sua dificuldade em

desvencilhar-se da menoridade que para ele se tornou quase uma natureza. Chegou mesmo a criar amor a ela, sendo por ora realmente incapaz de utilizar seu próprio entendimento, porque nunca o deixaram fazer a tentativa de assim proceder. Preceitos e fórmulas, estes instrumentos mecânicos do uso racional, ou

\footnotetext{
${ }^{36}$ KANT, Immanuel. O conflito das faculdades, p. 101 e 104

${ }^{37}$ KANT, Immanuel. Idéia de uma história universal de um ponto de vista cosmopolita, p. 17 e 18

${ }^{38}$ WOOD, Allen W. "Kant's philosophy of history". In: KLEINGELD, Pauline (org). "Toward perpetual peace" and other writings on politics, peace, and history. New York: Yale University Press, 2006, p. 257-258

${ }^{39}$ KANT, Immanuel. "Resposta à pergunta: Que é 'Esclarecimento’? (Aufklärung)”. In: KANT, Immanuel. Textos seletos. Petrópolis: Vozes, 2009, p. 64
}

\begin{tabular}{|c|c|c|c|c|c|}
\hline intuitio & $\begin{array}{c}\text { ISSN } \\
1983-4012\end{array}$ & Porto Alegre & Vol.8 $-\mathrm{N}^{\mathrm{o}} .2$ & $\begin{array}{c}\text { Dezembro } \\
2015\end{array}$ & p.25-42 \\
\hline
\end{tabular}


A ideia do direito e a sua efetivação como pressupostos da paz perpétua de Kant

antes do abuso, de seus dons naturais, são os grilhões de uma perpétua menoridade (grifos meus) ${ }^{40}$.

Por sua vez, a figura do sinal histórico do progresso apresenta alguns ganhos cognitivos e motivacionais $^{41}$ em relação ao expediente heurístico do "propósito da natureza". Primeiramente, é possível dizer que este novo expediente considera em amplo espectro a condição humana de homo noumenon e homo phaenomenon, a qual é fundamento do sistema filosófico kantiano ${ }^{42}$. Segundo, ele encontra na ideia de estado de direito a "causa a priori" e no modo de pensar dos espectadores da revolução constitucional francesa o "efeito a posteriori" do progresso. Terceiro, ele mostra que o progresso para melhor é factível na história e decorrente do próprio aprendizado e trabalho humanos. Quarto, ele apresenta-se como uma imagem menos negativa, mais politizada e mais fácil de ser lembrada pelas gerações vindouras. Nas palavras de Zingano, ele é "uma instância à qual podemos sempre recorrer como fato prático, portanto como preenchendo a aparente inanidade da efetividade moral" (grifos meus) ${ }^{43}$, mostrando-se, conforme outrora argumentado, como um forte indício do progresso para melhor que, em razão das suas particulares características $^{44}$, pode ser facilmente rememorado, porque

De facto, tal acontecimento é demasiado grande, demasiado entretecido com o interesse da humanidade e, segundo a sua influência, demasiado propalado no mundo em todas as suas partes para, entre os povos, não ter de ser despertado na memória e na repetição de novos intentos desta índole, em qualquer ocasião de circunstâncias favoráveis ${ }^{45}$.

Seja por um ou por outro motivo, o que se tem em grande conta é que agora Kant não se satisfaz plenamente com a subsidiariedade da fórmula heurística da natureza, como motor da realização da ideia do direito, e nem mais com a verificação de fracos indícios históricos da sua efetivação no mundo, mas

\footnotetext{
${ }^{40}$ KANT, Immanuel. "Resposta à pergunta: Que é ‘Esclarecimento'? (Aufklärung)”, p. 64

${ }^{41}$ Wood explica que a finalidade da teoria é encontrar modelos de motivação e ação humanas que tenham eficácia histórica e que sejam distintos de fatores acidentais na escolha humana. WOOD, Allen W. Kant's philosophy of history, p. 259. Nesse sentido, Hannah Arendt afirma que a noção moderna de teoria indica "uma hipótese de trabalho que muda conforme os resultados que produz e que depende, para sua validade, não do que 'revela', mas do fato de 'funcionar"'. ARENDT, Hannah. Entre o passado e o futuro. 7 ed. São Paulo: Perspectiva, 2011, p. 68. Ora, se os modelos de ação e motivação humanas primam pela eficácia, pode-se afirmar que nada é mais honesto, por parte do pesquisador da era moderna, do que buscar aqueles modelos que apresentam mais eficácia em relação a outro e, por isso, se adaptam melhor às exigências do empreendimento teórico.

${ }^{42}$ KANT, Immanuel. A metafísica dos costumes, p. 85. Nesse sentido, Karine Salgado pontua que o projeto de paz kantiano "não foi desenvolvido para uma 'comunidade de anjos', mas para o homem e sua dualidade natural de razão e sensibilidade". SALGADO, Karine. A paz pérpetua de Kant: atualidade e efetivação. Belo Horizonte: Mandamentos/FUMEC, 2008, p. 21.

${ }^{43}$ ZINGANO, Marco Antônio. Razão e história em Kant. São Paulo: Brasiliense, 1989, p. 272.

${ }^{44} \mathrm{O}$ signo demonstrativo indica a causalidade entre dois fatos (a fumaça indica o fogo), o rememorativo faz presente aquilo que se passou (túmulos recordam os mortos) e o prognóstico, considerando a transitoriedade do presente, acolhe este, que já se tornou passado, numa perspectiva projetada no futuro em vista, principalmente, das suas consequências. KANT, Immanuel. Antropologia de um ponto de vista pragmático. São Paulo: Iluminuras, 2006, p. 91-92.

${ }^{45}$ KANT, Immanuel. $O$ conflito das faculdades, p. 105.
}

\begin{tabular}{|c|c|c|c|c|c|}
\hline intuitio & $\begin{array}{c}\text { ISSN } \\
1983-4012\end{array}$ & Porto Alegre & Vol.8 $-\mathrm{N}^{\mathrm{o}} .2$ & $\begin{array}{c}\text { Dezembro } \\
2015\end{array}$ & p.25-42 \\
\hline
\end{tabular}


A ideia do direito e a sua efetivação como pressupostos da paz perpétua de Kant

tenta encontrar um substituto probatório, a "prova", a "demonstração", a "ocorrência", da concretização desta ideia em solo social e institucional, o que mostra, segundo Honneth, que Kant já havia ensaiado uma “tentativa de 'destranscendentalizar' a razão prática, situando-a historicamente" ${ }^{46}$, uma vez que os princípios da lei moral não são mais tratados somente como imperativos deslocados do espaço e tempo, mas, também, como causas de transformações institucionais que, por assim dizer, possuem características empíricas ou históricas ${ }^{47}$. Com efeito, nota-se que essa tentativa de destranscendentalização da razão, promovida por Kant em $O$ conflito das faculdades, é precedida de algumas tentativas menos pretensiosas iniciadas com a sua referência aos "débeis indícios" do progresso na Ideia de uma história universal de um ponto de vista cosmopolita, passando pela sua afirmação de que "há muitas provas de que o gênero humano no seu conjunto progrediu efectivamente e de modo notável sob todas as épocas anteriores" (grifo meu $)^{48}$, em Sobre a expressão corrente, até chegar à sua figura do sinal histórico em $O$ conflito das faculdades.

Conforme Honneth, nos escritos Resposta à pergunta: Que é "Esclarecimento"? e O conflito das faculdades de Kant, que não fazem qualquer menção ao "propósito da natureza", é possível ver um terceiro modelo alternativo e não oficial (modelo hermenêutico ou explicativo) de sua filosofia da história, pelo qual Kant tem a visão de um público esclarecido (participante ativo e participante observador) a respeito de um processo de transformação político-moral, o qual substitui a matriz teleológica da sua filosofia da história por um "princípio de organização narrativa da autocertificação histórica no processo politicamente motivado de esclarecimento" ${ }^{49}$. Agora, por essa terceira perspectiva insinuada por Honneth, a efetivação histórica da ideia do direito é dirigida pelo processo histórico de aprendizagem humana, e não mais pela intenção finalística da natureza ${ }^{50}$.

Ao referir-se também à obra Pedagogia de Kant, Honneth esclarece que, de um modo geral e dentro de circunstâncias mais ou menos adequadas, as crianças são instigadas a apropriar-se do estoque acumulado de razões produzidas em seu meio sociocultural mediante a ajuda de seus educadores e, ainda, que há sempre certa capacidade de aprendizado acumulada em todo nível histórico. No entanto, mais do que apenas reproduzir o saber social criado pela geração anterior, as gerações futuras enriquecem e ampliam o saber recebido, sendo que, sob estas condições, a história humana poderia ser compreendida em seu todo como um "mecanismo de aprendizagem que abrange gerações [...] como um processo

\footnotetext{
46 “attempt to 'de-transcendentalize' pratical reason by situating it historically". HONNETH, Axel. Pathologies of reason: on legacy of critical theory, p. 194

${ }^{47}$ HONNETH, Axel. Pathologies of reason: on legacy of critical theory, p. 11

${ }^{48}$ KANT, Immanuel. "Sobre a expressão corrente", p. 105

49" narrative organizational principle of historical self-reassurance in the politically driven process of enlightenment". HONNETH, Axel. Pathologies of reason: on legacy of critical theory, p. 10

${ }^{50} \mathrm{HONNETH}$, Axel. Pathologies of reason: on legacy of critical theory, p. 12-14
}

\begin{tabular}{|c|c|c|c|c|c|}
\hline intuitio & $\begin{array}{c}\text { ISSN } \\
1983-4012\end{array}$ & Porto Alegre & Vol.8 $-\mathrm{N}^{\circ} .2$ & $\begin{array}{c}\text { Dezembro } \\
2015\end{array}$ & p.25-42 \\
\hline
\end{tabular}


A ideia do direito e a sua efetivação como pressupostos da paz perpétua de Kant

cognitivo de progresso: de fato, como um desdobramento de racionalização moral" ${ }^{, 51}$. Todavia, Honneth afirma que Kant não é ingênuo o bastante para desconsiderar a imagem sombria que tem a respeito da história humana, prevendo, assim, que o processo de progressão acumulativa da razão pode ser bloqueado ou interrompido por conta da "constituição habitual da natureza humana",52 que, em sua forma negativa, é representada pelas célebres figuras da "preguiça" e da "covardia", o que vai de encontro com as nossas afirmações acima colocadas. Além disso, é interessante observar que Kant, em Sobre a expressão corrente, já havia afirmado a possibilidade da interrupção do progresso ${ }^{53}$.

Contudo, notamos que as nossas primeiras percepções e igualmente as de Honneth, de que a figura do "propósito da natureza" é praticamente abandonada por Kant em $O$ conflito das faculdades, não são totalmente adequadas, pois, apesar de Kant não fazer referência alguma à "natureza" e ao seu "fim último", ele ainda requer o socorro positivo da Providência para garantir o progresso para o melhor. Segundo o próprio Kant, a boa educação voltada para o progresso para o melhor "é um plano que dificilmente permite esperar o êxito desejado" ${ }^{, 54}$ porque nem o povo tampouco o Estado, cada qual pelos seus motivos, querem suportar os altos custos da educação da juventude. Embora um plano educacional voltado para o bem devesse ser abraçado pelo poder político soberano que, mediante reformas paulatinas do Estado, avançaria constantemente rumo ao melhor, Kant considera que, se são homens os que devem realizar a educação e se estes foram anteriormente educados de forma a desprezar a necessidade de investimentos na educação, tem-se um círculo vicioso que só pode ser quebrado pelo auxílio positivo de uma "sabedoria do Alto", da "Providência",55, exigindo-se, por sua vez, dos homens

simplesmente uma sabedoria negativa para o fomento de tal fim, a saber, que se vejam forçados a tornar a guerra, o maior obstáculo do moral, que leva sempre este a retroceder, primeiro, paulatinamente mais humana, em seguida, mais rara e, por fim, a desvanecer-se de todo como guerra ofensiva, de modo a enveredar por uma constituição que, por sua natureza, sem se enfraquecer, e fundada em genuínos princípios de direito, possa avançar com consistência para o melhor ${ }^{56}$.

É possível supor que Kant não abandonou totalmente a figura auxiliar do "propósito da natureza" porque aquele "modo de pensar" advindo do evento da Revolução Francesa, no qual se baseia o expediente do sinal histórico, ainda lhe era uma ocorrência sociopolítica muito próxima para oferecer-lhe um respaldo empírico suficientemente estável e enraizado para compor o sinal histórico e, assim, motiválo a deixar por completo o princípio heurístico-regulativo da "natureza", fazendo-nos lembrar da ilustre

\footnotetext{
51 "mechanism of learning spanning the generations [...] as a cognitive process of progress: indeed, as the unfolding of moral rationalization". HONNETH, Axel. Pathologies of reason: on legacy of critical theory, p. 14-15

52 "habitual constitution of human nature". HONNETH, Axel. Pathologies of reason: on legacy of critical theory, p. 15.

${ }^{53}$ Cf. KANT, Immanuel. "Sobre a expressão corrente", p. 103.

${ }^{54}$ KANT, Immanuel. O conflito das faculdades, p. 110.

${ }^{55}$ KANT, Immanuel. O conflito das faculdades, p. 110-111.

${ }^{56}$ KANT, Immanuel. O conflito das faculdades, p. 111.
}

\begin{tabular}{|c|c|l|l|c|c|}
\hline intuitio & $\begin{array}{c}\text { ISSN } \\
1983-4012\end{array}$ & Porto Alegre & Vol.8 $-\mathrm{N}^{\circ} .2$ & $\begin{array}{c}\text { Dezembro } \\
2015\end{array}$ & p.25-42 \\
\hline
\end{tabular}


A ideia do direito e a sua efetivação como pressupostos da paz perpétua de Kant

metáfora de Hegel que pontua que a Coruja de Minerva só levanta vôo ao entardecer. Não obstante isso, é possível dizer que a "natureza", em $O$ conflito das faculdades, tem a sua subsidiariedade consideravelmente mitigada em relação aos escritos Sobre a expressão corrente e A paz perpétua, o que, de certa forma, torna plausíveis as afirmações de Honneth de que Kant estava a caminho da "destranscendentalização" da razão prática ao tentar, comedidamente, vincular a ideia de progresso para melhor e, com isso, a ideia do direito, a um processo de aprendizagem político-cultural, fundamentado na aptidão humana para o livre discernimento, que poderia ser interrompido, mas jamais extinto ${ }^{57}$.

\section{O Direito e seus elementos (coerção e publicidade) como condition sine qua non da paz perpétua}

Embora o pensamento de Kant varie a respeito do modo de efetivação da ideia do direito que, desde a Ideia de uma história universal de um ponto de vista cosmopolita até $O$ conflito das faculdades, sofreu consideráveis modificações conceituais, é bastante perceptível que a ideia de uma ordem cosmopolita de paz perpétua, sem a qual dificilmente os seres humanos conseguirão alcançar a sua destinação primordial, que é a sua convivência num "sistema moralmente fundado", sempre foi um objetivo constante de seus escritos político-filosóficos. Nesse passo, considerando que, para Kant, somente o direito pode garantir relações pacíficas entre os homens em um Estado (direito político), entre Estado e Estado (direito das gentes) e entre os homens e os Estados (direito cosmopolita) ${ }^{59}$, e que, nas palavras de Klemme, o conceito de direito racional é "a chave para a interpretação kantiana da paz

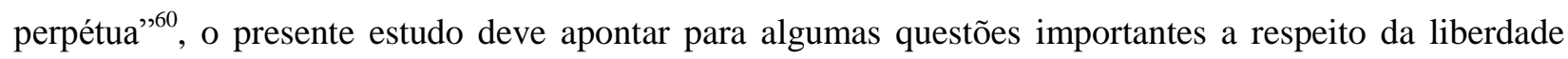
externa limitada pela lei ${ }^{61}$, principalmente conforme os textos Sobre a expressão corrente, A paz perpétua e Doutrina do direito, pois nesses escritos a ideia de uma ordem cosmopolita pacífica e justa é fundamentada na ideia a priori do direito, e não em acordos patologicamente extorquidos como ocorre na Ideia de uma história universal de um ponto de vista cosmopolita.

\footnotetext{
${ }^{57}$ HONNETH, Axel. Pathologies of reason: on legacy of critical theory, p. 14-18. Honneth afirma que, embora não seja essa a sua intenção, a sua leitura da filosofia da história kantiana, que mostra a tentativa de Kant de "destranscendentalizar" a razão prática, destrói o sistema da filosofia kantiana por mostrar a alocação da razão prática em instituições sociais concretas. Todavia, esse receio de Honneth pode ser afastado se considerarmos, com Christian Hamm, que os sinais históricos não podem de forma alguma "provar" o progresso humano para melhor e, por isso, também a concretização da ideia do direito - mas, quando muito, a disposição moral da humanidade que é apenas uma pressuposição para a promoção do progresso. HAMM, Christian. "Sobre a sistematizabilidade da filosofia da história de Kant”, p. 84.

${ }^{58}$ KANT, Immanuel. Crítica da faculdade do juízo, p. 273.

${ }^{59}$ KLEMME, Heiner. "Filosofia política de Kant - moral e direito na perspectiva histórica e futura", p. 28.

${ }^{60}$ KLEMME, Heiner. "Filosofia política de Kant - moral e direito na perspectiva histórica e futura", p. 46.

${ }^{61}$ Todavia, tem-se claro que o direito para Kant também é dependente de uma dinâmica interna, segundo a qual os homens têm o dever de estabelecer o direito público e trabalhar para o seu aperfeiçoamento. KLEMME, Heiner. "Filosofia política de Kant - moral e direito na perspectiva histórica e futura", p. 28.
}

\begin{tabular}{|c|c|l|l|c|c|}
\hline intuitio & $\begin{array}{c}\text { ISSN } \\
1983-4012\end{array}$ & Porto Alegre & Vol.8 $-\mathrm{N}^{\mathrm{o} .2}$ & $\begin{array}{c}\text { Dezembro } \\
2015\end{array}$ & p.25-42 \\
\hline
\end{tabular}


A ideia do direito e a sua efetivação como pressupostos da paz perpétua de Kant

Influenciado pelo pensamento hobbesiano, Kant entende que o estado de natureza (status naturalis $)^{62}$ não é um estado de paz e segurança, mas uma situação anárquica, de convivência precária e de ininterrupto temor de hostilidades ${ }^{63}$. Nele, vigora um estado de liberdade em que as "leis sobre o meu e o teu [...] prescrevem precisamente o mesmo que prescrevem no estado civil”, porém neste último estado "são oferecidas as condições sob as quais aquelas leis alcançam efectivação (de acordo com a justiça distributiva)"64. Ele não é um "estado de injustiça (iniustus)", mas um "estado desprovido de Direito"65. Em razão da ausência de leis juridicamente estabelecidas, os homens não encontram limites para a sua liberdade externa e, por isso, decidem de forma particular o que é bom para si independentemente daquilo que é bom para os outros, o que os leva a ver suas pretensões anuladas face às reivindicações dos outros, uma vez que, nesse estado, cada qual é árbitro de si próprio quando em conflito com os demais. Dessa forma, impera uma condição de ameaça constante de guerra e de insegurança entre os homens ${ }^{66}$. Nas palavras de Kant, o estado de natureza "é antes um estado de guerra, isto é, um estado em que, embora não exista sempre uma explosão das hostilidades, há sempre, no entanto, uma ameaça constante"67.

Para Kant, a injustiça não reside no preparo estratégico para confrontar as possíveis e eventuais hostilidades alheias, pois ninguém é obrigado a amargar a experiência de ver-se espoliado para então tornar-se prudente, nem no uso da coerção particular para afastar as ameaças e as investidas violentas dos outros, tampouco no fato de cada um julgar-se o magistrado competente para decidir sobre a sua causa no status naturalis, mas sim na intenção de permanecer numa condição de ausência de Direito, na qual reinaria um estado de plena insegurança, porque nela ninguém estaria protegido contra a violência ${ }^{68}$. Assim, o abandono do estado de natureza, mediante a instituição de uma sociedade civil, seria o primeiro

\footnotetext{
${ }^{62}$ Não é demais esclarecer que o estado de natureza não é uma construção a partir da experiência a respeito da violência humana, mas uma ideia da razão assentada a priori na condição puramente racional de que, sem a coerção das leis públicas, os homens e Estados vivem a ameaça constante de violência recíproca. KANT, Immanuel. A metafísica dos costumes, p. 176-178.

${ }^{63}$ De acordo com o seu diagnóstico do estado de natureza, Kant concorda com o pensamento de Hobbes de que tal condição de guerra de todos contra todos é o summum malum para a humanidade. Além disso, Kant também concorda com Hobbes que tal problema pode ser resolvido com a instituição de um estado jurídico. No entanto, enquanto Hobbes alude ao bem-estar dos homens como motivo para a renúncia ao estado de natureza, Kant rompe com a concepção hobbesiana de interesse racional próprio ao entender que o ingresso no status civilis não é dirigido pela racionalidade instrumental, mas sim pelo dever moral-legal dos homens. KLEMME, Heiner. "Filosofia política de Kant - moral e direito na perspectiva histórica e futura", p. 44.

${ }^{64}$ KANT, Immanuel. A metafisica dos costumes, p. 176-178.

${ }^{65}$ KANT, Immanuel. A metafísica dos costumes, p. 177. Em sentido contrário, Wood entende que o estado de natureza já é um estado de injustiça, porque nele não tem qualquer importância o que as pessoas escolhem fazer com a sua liberdade sem Direito. WOOD, Allen W. Kantian ethics. Cambridge: Cambridge University Press, 2008, p. 215. Já segundo Ricardo Terra a injustiça não está alocada no próprio estado de natureza, mas na ausência de disposição para superar esse estado em favor do Estado civil. TERRA, Ricardo R. A política tensa: idéia e realidade na filosofia da história de Kant, p. 33.

${ }^{66}$ KANT, Immanuel. A metafísica dos costumes, p. 170-178.

${ }^{67}$ KANT, Immanuel. “A paz perpétua”, p. 136 e 137.

${ }^{68}$ Cf. KANT, Immanuel. A metafísica dos costumes, p. 170-177.
}

\begin{tabular}{|c|c|l|l|c|c|}
\hline intuitio & $\begin{array}{c}\text { ISSN } \\
1983-4012\end{array}$ & Porto Alegre & Vol.8 $-\mathrm{N}^{\mathrm{o}} .2$ & $\begin{array}{c}\text { Dezembro } \\
2015\end{array}$ & p.25-42 \\
\hline
\end{tabular}


A ideia do direito e a sua efetivação como pressupostos da paz perpétua de Kant

passo a ser dado pelos homens em direção ao ideal cosmopolita de paz perpétua ${ }^{69}$, pois, segundo Kant, a condição de possibilidade do direito das gentes encontra-se justamente na existência de um estado jurídico prévio sem o qual não há qualquer direito público, mas somente o direito privado (direito no estado de natureza) ${ }^{70}$, o que o leva a relacionar, entre os deveres de direito, o dever de participar de uma comunidade jurídica pela qual "cada um possa manter aquilo que é seu (suum cuique tribue)",71. Em verdade, Kant é ainda mais austero quando afirma que se o conceito racional do direito estiver ausente em qualquer uma das três formas possíveis de estado jurídico (direito político, das gentes e cosmopolita), a estrutura das demais será necessariamente corrompida e, por fim, destruída ${ }^{72}$. Nesse sentido, Georg Cavallar, ao discorrer sobre os três artigos definitivos do opúsculo A paz perpétua, afirma que somente "quando predominar um estado de direito público em todas as três áreas, que assegure a cada indivíduo ou a cada estado o seu direito, poderá haver a paz"73.

De fato, os indivíduos devem ingressar num “estado jurídico" (estado de justiça distributiva), mediante a construção e instauração de uma ordem jurídica comum, cujo fundamento decorre analiticamente do conceito de direito nas relações externas ${ }^{74}$ que tem como princípio universal o dever de agir "exteriormente de tal modo que o uso livre do teu arbítrio possa coexistir com a liberdade de cada um segundo uma lei universal" 75 e que pode ser definido como "o conjunto das condições sob as quais o arbítrio de cada uma pode conciliar-se com o arbítrio de outrem segundo uma lei universal da liberdade"76. Dessa forma, diferentemente de Hobbes, que argumenta a favor do direito com base em interesses empíricos, nota-se que o direito para Kant não é fundamentado em condições factuais. A alusão às prescrições contidas nas leis positivas - instituídas em determinado tempo e lugar - não basta para reconhecer o critério universal, puro e a priori, pelo qual se pode estabelecer o certo e o errado em cada caso particularizado. Ainda que as leis positivas sejam excelentes diretrizes para se estabelecer a base de qualquer produção legislativa, caso os juristas pretendam buscar soluções universais para o direito, esses deveriam abandonar os princípios empíricos do direito positivo para, então, procurar as suas fontes apriorísticas exclusivamente na razão ${ }^{77}$, porque, conforme Höffe, "a experiência não é somente mutável,

\footnotetext{
${ }^{69}$ KLEMME, Heiner. "Filosofia política de Kant - moral e direito na perspectiva histórica e futura", p. 46

${ }^{70}$ KANT, Immanuel. “A paz perpétua”, p. 183.

${ }^{71}$ KANT, Immanuel. A metafísica dos costumes, p. 83.

${ }^{72}$ KANT, Immanuel. A metafísica dos costumes, p. 176.

${ }^{73}$ CAVALLAR, Georg. "A sistemática da parte jusfilosófica do projeto kantiano À paz perpétua". In: ROHDEN, Valério (coord.). Kant e a instituição da paz. Porto Alegre: Ed. Universidade/UFRGS, Goethe-Institut/ICBA, 1997, p. 84.

${ }^{74}$ KANT, Immanuel. A metafísica dos costumes, p. 170-171.

${ }^{75}$ KANT, Immanuel. A metafísica dos costumes, p. 44.

${ }^{76}$ KANT, Immanuel. A metafísica dos costumes, p. 43.

${ }^{77}$ KANT, Immanuel. A metafísica dos costumes, p. 42.
}

\begin{tabular}{|c|c|c|c|c|c|}
\hline intuitio & $\begin{array}{c}\text { ISSN } \\
1983-4012\end{array}$ & Porto Alegre & Vol.8 $-\mathrm{N}^{\mathrm{o}} .2$ & $\begin{array}{c}\text { Dezembro } \\
2015\end{array}$ & p.25-42 \\
\hline
\end{tabular}


A ideia do direito e a sua efetivação como pressupostos da paz perpétua de Kant

mas além disso muito duvidosa. Também na fundamentação (não na aplicação) do Direito, ela é a 'mãe da ilusão" $"$.

No entanto, para que o direito tenha eficácia, Kant entende que o vínculo entre coerção recíproca universal e liberdade de todos é um fundamento necessário sobre o qual se assenta o próprio conceito de direito, uma vez que a "lei de uma coerção recíproca que está necessariamente de acordo com a liberdade de cada um sob o princípio da liberdade universal é [...] a construção daquele conceito, quer dizer, algo como a sua representação na pura intuição a priori" ${ }^{\text {79 }}$. Por assim dizer, a faculdade de coerção é um elemento imprescindível e aprioristicamente válido que tem a função de garantir o uso recíproco da liberdade, na medida em que torna legítima toda ação que respeita a liberdade dos outros, e, consequentemente, tornar "possível uma constituição política conforme o direito" ${ }^{80}$. Sem ela é impossível construir uma ordem jurídica que tenha por fim assegurar a convivência de arbítrios, porque, conforme explica Maus, no entender de Kant "a fundação do Estado repousa simples e praticamente, no poder ao qual se deve o caráter coercitivo do Direito de toda a res publica phaenomenon"81.

Com efeito, Kant chega a afirmar que o direito e a faculdade de coagir significam uma mesma $\operatorname{coisa}^{82}$, porque efetivamente uma condição jurídica só pode dar-se quando a liberdade jurídica de ação das pessoas é resguardada por uma autoridade que impõe limites às ações externas de todos, ou seja, que executa atos que restringem ações ilícitas que impedem o exercício lícito da liberdade. Dessa forma, para que exista um status civilis é de suma importância que os poderes estatais sejam capazes de limitar a liberdade de ação dos seus cidadãos, coagindo estes a se respeitarem juridicamente. Portanto, o direito de coagir é derivado de algo que é essencial para o direito racional - decorre da coexistência livre dos arbítrios conforme uma lei universal -, o que mostra que o conceito de direito envolve, analiticamente, a autorização para empregar a coerção contra a ilicitude que, assim sendo, torna-se igualmente uma proposição analítica ${ }^{83}$ ou, nas palavras de Kant, "os conceitos da razão querem apenas fundar a coacção legal segundo os princípios da liberdade" ${ }^{\natural 4}$.

Não obstante a coerção tenha a função primordial de garantir a convivência dos arbítrios, mediante a restrição do uso ilícito da liberdade, o caráter crítico da filosofia kantiana impede que ela imponha limitações de qualquer forma ao uso público da razão - "A liberdade de pensar contrapõe-se, em primeiro lugar, à coacção civil ${ }^{, 85}$, diz Kant - , exigindo do direito racional que toda pretensão jurídica

\footnotetext{
${ }^{78}$ HÖFFE, Otfried. Immanuel Kant. São Paulo: Martins Fontes, 2005, p. 233.

${ }^{79}$ KANT, Immanuel. A metafísica dos costumes, p. 46.

${ }^{80}$ KANT, Immanuel. “A paz perpétua”, p. 169.

${ }^{81}$ MAUS, Ingeborg. O direito e a política: teoria da democracia. Belo Horizonte: Del Rey, 2009, p. 268.

${ }^{82}$ KANT, Immanuel. A metafísica dos costumes, p. 46.

${ }^{83}$ WOOD, Allen W. Kantian ethics, p. 215-216.

${ }^{84}$ KANT, Immanuel. "A paz perpétua”, p. 169.

${ }^{85}$ KANT, Immanuel. "Que significa orientar-se no pensamento?” In: KANT, Immanuel. A paz perpétua e outros opúsculos. Lisboa: Edições 70, 2009, p. 54.
}

\begin{tabular}{|c|c|c|c|c|c|}
\hline intuitio & $\begin{array}{c}\text { ISSN } \\
1983-4012\end{array}$ & Porto Alegre & Vol.8 $-\mathrm{N}^{\mathrm{o}} .2$ & $\begin{array}{c}\text { Dezembro } \\
2015\end{array}$ & p.25-42 \\
\hline
\end{tabular}


A ideia do direito e a sua efetivação como pressupostos da paz perpétua de Kant

tenha fundamento na forma da publicidade que, segundo Habermas, é, ao mesmo tempo, diretriz de ordenação jurídica e método de esclarecimento ${ }^{86}$. Como método de ilustração, o uso público da razão tem o condão de garantir aos homens a "liberdade de comunicar publicamente seus pensamentos" e, com isso, proteger a "liberdade de pensar", e a possibilidade de correção dos seus pensamentos ${ }^{87}$. Essa liberdade de

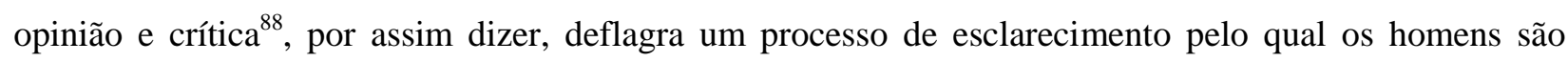
habilitados a servir-se do seu próprio entendimento, sem a orientação de outrem, para deixar a menoridade da qual são eles próprios inteiramente culpados ${ }^{89}$.

Por sua vez, este processo de autocompreensão de homens livres que se influenciam reciprocamente ${ }^{90}$ produz efeitos na esfera política, na medida em que promove a constituição de uma esfera pública de cidadãos e, também, a expansão da compreensão política do governante, os quais (cidadãos e governantes) são levados a fundamentar as máximas das suas ações conforme as ideias político-jurídicas ou, nas palavras de Habermas, os homens constituem-se “em público dos 'cidadãos', no qual ficam se entendendo sobre as questões da res publica. Essa esfera pública politicamente em funcionamento torna-se, sob a 'constituição republicana', um princípio de organização do Estado liberal de Direito" de liberdade" e na propensão humana de "comunicar reciprocamente" tudo o que lhe diz respeito, exige que o soberano conceda aos cidadãos a liberdade de opinião para manifestar publicamente as injustiças que lhe são perceptíveis nas leis positivas, sendo que qualquer medida de restrição desta liberdade prejudica o conhecimento pelo próprio soberano daquilo que é preciso ser reformado no Estado, deixando, por conseguinte, de favorecer o seu principal objetivo ${ }^{92}$. Nesse sentido, Terra explica:

Dessa forma expande-se o conhecimento, e o próprio soberano pode buscar elementos para aumentar sua compreensão das coisas públicas e pode dirigir com clareza o processo das reformas, que constituem uma obrigação jurídica e são provocadas pelo antagonismo das disposições naturais do homem ${ }^{93}$.

\footnotetext{
${ }^{86}$ HABERMAS, Jürgen. Mudança estrutural da esfera pública: investigações quanto a uma categoria da sociedade burguesa. 2 ed. Rio de Janeiro: Tempo Brasileiro, 2003, p. 128.

${ }^{87}$ KANT, Immanuel. "Que significa orientar-se no pensamento?", p. 54.

${ }^{88}$ Sobre a liberdade de opinião e o irrestrito direito à crítica do publicum como fundamentos do direito e da política: GERHARDT, Volker. "Uma teoria crítica da política sobre o projeto kantiano À paz perpétua". In: ROHDEN, Valério (coord.). Kant e a instituição da paz. Porto Alegre: Ed. Universidade/UFRGS, Goethe-Institut/ICBA, 1997, p. 45 .

${ }^{89}$ KANT, Immanuel. "Resposta à pergunta: que é o iluminismo?" In: KANT, Immanuel. A paz perpétua e outros opúsculos. Lisboa: Edições 70, 2009, p. 9-16.

${ }_{90}^{90}$ KANT, Immanuel. "Sobre a expressão corrente", p. 78.

${ }^{91}$ HABERMAS, Jürgen. Mudança estrutural da esfera pública: investigações quanto a uma categoria da sociedade burguesa, p. 131.

${ }^{92}$ KANT, Immanuel. "Sobre a expressão corrente", p. 97-99.

${ }^{93}$ TERRA, Ricardo R. A política tensa: idéia e realidade na filosofia da história de Kant, p. 174.
}

\begin{tabular}{|c|c|c|c|c|c|}
\hline intuitio & $\begin{array}{c}\text { ISSN } \\
1983-4012\end{array}$ & Porto Alegre & Vol.8 $-\mathrm{N}^{\mathrm{o} .2}$ & $\begin{array}{c}\text { Dezembro } \\
2015\end{array}$ & p.25-42 \\
\hline
\end{tabular}


A ideia do direito e a sua efetivação como pressupostos da paz perpétua de Kant

O princípio transcendental da publicidade, portanto, está contido em toda pretensão jurídica e tem por finalidade tornar cognoscível a priori a injustiça daquelas pretensões que podem afetar negativamente o direito de todos os cidadãos de um Estado ${ }^{94}$, sendo expresso por Kant na seguinte fórmula: "São injustas todas as acções que se referem ao direito de outros homens cujas máximas não se harmonizem com a publicidade ${ }^{, 95}$. Entretanto, apesar da publicidade da máxima de uma ação ser conditio sine qua non da sua legalidade, Kant deixa claro que nem toda pretensão jurídica levada ao crivo da publicidade é por si só justa $^{96}$, uma vez que para tanto é imprescindível a consonância entre política e teoria do direito, a qual somente pode dar-se efetivamente no âmbito de uma união federativa dos Estados ${ }^{97}$. Dessa forma, o princípio da publicidade, que, por ser transcendental, prescinde de todo elemento empírico ${ }^{98}$, tem a função de atuar como medium, entre política e teoria do direito, dentro do qual deve realizar-se a reunião inteligível dos fins empíricos de $\operatorname{todos}^{99}$, aparecendo, nesse sentido, uma segunda formulação kantiana da publicidade como princípio do direito público: “Todas as máximas que necessitam da publicidade (para não fracassarem no seu fim) concordam simultaneamente com o direito e a política" ${ }^{\text {100 }}$. Ou seja, segundo Kant, para não se dar azo a uma "política tenebrosa", a política e o direito devem ser unificados na forma da publicidade para que os fins daquela não transgridam os fins deste ${ }^{101}$.

\section{Considerações finais}

Em resposta às questões inicialmente colocadas, mostramos que, de fato, os argumentos de Kant oscilam entre delegar a efetivação da sociedade civil à "natureza" ou outorgá-la ao dever moral dos homens. Também, evidenciamos a leitura de Honneth, segundo a qual é possível compreender que Kant caminha em direção da "destranscendentalização" da razão prática quando procura fincar a ideia do direito em solo institucional e entendê-la com um processo de aprendizagem político-cultural que envolve diversas gerações. Ainda, mostramos que a ideia do direito é a base da ideia de paz duradora e que ela depende da ideia de coerção legal, a qual, contudo, não pode impor qualquer limite ao uso público da razão, pois isso

\footnotetext{
${ }^{94}$ Esclareça-se que a forma da publicidade também tem por objetivo mostrar a priori as ilegalidades das pretensões jurídicas nas relações entre os Estados (direito das gentes) e entre os homens e os Estados (direito cosmopolita). KANT, Immanuel. "A paz perpétua”, p. 180-185.

${ }^{95}$ KANT, Immanuel. A paz perpétua, p. 178.

${ }^{96}$ Cf. KANT, Immanuel. A paz perpétua, p. 183.

${ }^{97}$ Cf. KANT, Immanuel. A paz perpétua, p. 183.

${ }^{98}$ Cf. KANT, Immanuel. A paz perpétua, p. 184-185.

${ }^{99}$ Cf. HABERMAS, Jürgen. Mudança estrutural da esfera pública: investigações quanto a uma categoria da sociedade burguesa, p. 140.

${ }^{100}$ KANT, Immanuel. A paz perpétua, p. 184.

${ }^{101}$ Cf. KANT, Immanuel. A paz perpétua, p. 184.
}

\begin{tabular}{|c|c|l|l|c|c|}
\hline intuitio & $\begin{array}{c}\text { ISSN } \\
1983-4012\end{array}$ & Porto Alegre & Vol.8 $-\mathrm{N}^{\mathrm{o}} .2$ & $\begin{array}{c}\text { Dezembro } \\
2015\end{array}$ & p.25-42 \\
\hline
\end{tabular}


A ideia do direito e a sua efetivação como pressupostos da paz perpétua de Kant

prejudicaria o princípio transcendental da publicidade que, também, é caracterizado como um dos pilares da ideia do direito e, portanto, da paz perpétua.

\section{Referências}

ARENDT, Hannah. Entre o passado e o futuro. 7 ed. São Paulo: Perspectiva, 2011.

FELDHAUS, Charles. Direito e moral: três estudos a respeito da filosofia prática de Kant. Florianópolis: Apolodoro, 2007.

FRANKENBERG, Günther; MOREIRA, Luiz (org.). Jürgen Habermas, 80 anos: direito e democracia. Rio de Janeiro: Lumen Juris, 2009.

HABERMAS, Jürgen. Mudança estrutural da esfera pública: investigações quanto a uma categoria da sociedade burguesa. 2 ed. Rio de Janeiro: Tempo Brasileiro, 2003.

HAMM, Christian. "Sobre a sistematizabilidade da filosofia da história de Kant". In: Veritas. Porto Alegre, v. 50, n. 1, Março/2005, p. 67-88.

HERRERO, Francisco Javier. Religião e história em Kant. São Paulo: Loyola, 1991.

HÖFFE, Otfried. A democracia no mundo de hoje. São Paulo: Martins Fontes, 2005.

HÖFFE, Otfried. Immanuel Kant. São Paulo: Martins Fontes, 2005.

HONNETH, Axel. Pathologies of reason: on legacy of critical theory. New York: Columbia University Press, 2009.

KANT, Immanuel. A Metafísica dos costumes. 2 ed. Lisboa: Fundação Calouste Gulbenkian, 2011.

KANT, Immanuel. Antropologia de um ponto de vista pragmático. São Paulo: Iluminuras, 2006.

KANT, Immanuel. A paz perpétua e outros opúsculos. Lisboa: Edições 70, 2009.

KANT, Immanuel. Crítica da faculdade do juízo. 2 ed. Rio de Janeiro: Forense Universitária, 2010.

KANT, Immanuel. Crítica da razão pura. 7 ed. Lisboa: Fund. Calouste Gulbekian, 2010.

KANT, Immanuel. Idéia de uma história universal de um ponto de vista cosmopolita. 2 ed. São Paulo: Martins Fontes, 2004.

KANT, Immanuel. $O$ conflito das faculdades. Lisboa: Edições 70, 1993.

KANT, Immanuel. Textos seletos. Petrópolis: Vozes, 2009.

KLEINGELD, Pauline. Kant and cosmopolitanism: the philosophical ideal of world citizenship. Cambridge: Cambridge University Press, 2011. http://dx.doi.org/10.1017/CBO9781139015486

KLEINGELD, Pauline (org). "Toward perpetual peace" and other writings on politics, peace, and history. New York: Yale University Press, 2006.

KLEMME, Heiner. "Filosofia política de Kant - moral e direito na perspectiva histórica e futura". In: Kant e-Prints, Campinas, Série 2, v. 5, n. 4, número especial, jul./dez., 2010, p. 08 - 61.

LOUDEN, Robert B. Kant's impure ethics: from rational beings to human beings. New York: Oxford University Press, 2000.

MAUS, Ingeborg. O direito e a política: teoria da democracia. Belo Horizonte: Del Rey, 2009.

MUNZEL, G. Felicitas. Kant's conception of moral character: the "critical" link of morality, anthropology, and reflective judgment. Chicago/London: The University of Chicago Press, 1999.

ROHDEN, Valério (coord.). Kant e a instituição da paz. Porto Alegre: Ed. Universidade/UFRGS, GoetheInstitut/ICBA, 1997.

SALGADO, Karine. A paz pérpetua de Kant: atualidade e efetivação. Belo Horizonte: Mandamentos/FUMEC, 2008.

TERRA, Ricardo R. A política tensa: idéia e realidade na filosofia da história de Kant. São Paulo: Iluminuras, 1995.

WEIL, Eric. Problemas kantianos. São Paulo: Realizações, 2012.

WOOD, Allen W. Kant. Porto Alegre: Artmed, 2008.

WOOD, Allen W. Kantian ethics. Cambridge: Cambridge University Press, 2008.

ZINGANO, Marco Antônio. Razão e história em Kant. São Paulo: Brasiliense, 1989.

Recebido em: 03/09/2014

Aprovado para a publicação em: 19/11/2015

\begin{tabular}{|c|c|l|l|c|c|}
\hline intuitio & $\begin{array}{c}\text { ISSN } \\
1983-4012\end{array}$ & Porto Alegre & Vol.8 $-\mathrm{N}^{\mathrm{o}} .2$ & $\begin{array}{c}\text { Dezembro } \\
2015\end{array}$ & p.25-42 \\
\hline
\end{tabular}

